\title{
Evaluation of growth and nutritional status in children and adolescents with extrahepatic portal vein obstruction and portal hypertension
}

\author{
Avaliação do estado nutricional e do crescimento \\ em crianças e adolescentes com obstrução \\ extra-hepática de veia porta \\ e hipertensão portal
}

Priscila Francisco MARQUES ${ }^{1}$

Maria Angela Bellomo BRANDÃO²

Gabriel HESSEL ${ }^{2}$

Roberta Vacari ALCANTARA ${ }^{2}$

Marcela Linden FERREIRA ${ }^{2}$

Elizete Aparecida LOMAZI²

A B S T R A C T

\section{Objective}

This study aims to evaluate dietary intake, nutritional status, and growth rate in children and adolescents with extrahepatic portal vein obstruction and portal hypertension.

\footnotetext{
1 Universidade Estadual de Campinas, Faculdade de Ciências Médicas, Programa de Pós-Graduação em Saúde da Criança e do Adolescente. R. Tessália Vieira de Camargo, 126, Cidade Universitária Zeferino Vaz, 13083-887, Campinas, SP, Brasil. Correspondencia para/Correspondence to: PF MARQUES. E-mail: <priscilafm_nutricionista@yahoo.com.br>.

2 Universidade Estadual de Campinas, Faculdade de Ciências Médicas, Departamento de Pediatria. Campinas, SP, Brasil. Support: Coordenação de Aperfeiçoamento de Pessoal de Nível Superior (Process no 01-P-2173/2012).

Article based on the master's thesis of PF MARQUES entitled: "Estado nutricional, ingestão alimentar e velocidade de crescimento de crianças e adolescentes com Obstrução Extra-Hepática de Veia Porta (OEHVP) e Hipertensão Portal (HP)". Universidade Estadual de Campinas; 2016.
} 


\section{Methods}

Outpatients aged 1 -18 years, diagnosed with extrahepatic portal vein obstruction and portal hypertension, who had no associated diseases, and who had not been subjected to a venous shunt were included in this study. Two evaluations were carried out in this study: an initial (evaluation 1) and a final evaluation (evaluation 2), with a three-month minimum interval between them. In each evaluation, dietary intake was analyzed comparing the results with recommended energy intake using the Harris \& Benedict equation and participants' anthropometric data, such as weight, height, mid-arm muscle circumference, weight-for-age, height-for-age, and body mass index-for-age, based on the World Health Organization 2006 standards.

\section{Results}

A total of 22 patients participated in this study. There was a significant improvement in weight, height, body mass index, and mid-arm muscle circumference measurements $(p<0.001 ; p<0.001 ; p<0.017 ; p=0.0018$ respectively) and in the relationship between dietary intake and energy recommended energy intake, according to the Harris $\&$ Benedict equation $(p=0.0001)$ from the first and second evaluation.

\section{Conclusion}

Extrahepatic portal vein obstruction and portal hypertension were not shown to be factors predisposing to malnourishment

Keywords: Child. Failure to thrive. Portal vein.

\section{R E S U M O}

\section{Objetivo}

Este estudo tem como objetivo avaliar a ingestão alimentar, o estado nutricional e a taxa de crescimento de crianças e adolescentes com obstrução extra-hepática de veia porta e hipertensão portal.

\section{Métodos}

Pacientes ambulatoriais com idades entre 1 e 18 anos, diagnóstico de obstrução extra-hepática de veia porta e hipertensão portal, sem patologias associadas e que não foram submetidos a um shunt venoso, foram incluídos neste estudo. O estudo compreendeu duas avaliações, no início (avaliação 1) e uma avaliação final (avaliação 2) com um intervalo mínimo de três meses entre ambos. Cada avaliação analisou a ingestão dietética comparando os resultados com as recomendações de energia usando a equação de Harris \& Benedict e os dados antropométricos dos participantes, tais como peso, altura, circunferência muscular do braço, peso por idade, altura por idade e índice de massa corpórea por idade utilizando a norma da Organização Mundial da Saúde de 2006.

\section{Resultados}

Participaram do estudo 22 pacientes. Foi observada uma melhora significativa entre a primeira e a segunda avaliação para as medidas de peso, estatura, índice de massa corporal e circunferência muscular do braço ( $p<0,001 ; p<0,001 ; p<0,017 ; p=0,0018$, respectivamente) e a relação de ingestão dietética e recomendação energética equação de Harris \& Benedict $(p=0,0001)$.

\section{conclusão}

Obstrução extra-hepática de veia porta e hipertensão portal não se mostraram como fatores predisponentes para desnutrição em nosso estudo.

Palavras-chave: Criança. Retardo de crescimento. Veia porta.

\section{INTRODUCTION}

Extrahepatic Portal Vein Obstruction (EHPVO) is the main cause of portal vein obstruction and can also occur due to presence of hepatocellular carcinoma or due to compression caused by extra-hepatic malignant tumors. Some authors consider EHPVO as the most common cause of portal hypertension in children, identified in $40 \%$ of gastrointestinal bleeding caused by esophageal varices, its main complication [1-3]. Considered as multifactorial, 
the EHPVO can occur in patients with hereditary predisposition to thrombophilic disorders, umbilical catheterization history, and neonatal sepsis, among other causes $[4,5]$.

The first presentations of EHPVO are splenomegaly and gastrointestinal bleeding, often diagnosed due to the presence of abdominal pain or complications related to hypersplenism $[5,6]$. Some authors have indicated that children with EHPVO may have growth retardation [6-8]. They have also argued that malnutrition results from chronic anemia due to bleeding and hypersplenism, intestinal venous congestion with concurrent malabsorption, and visceromegaly, which affects food acceptance. Another theory associated with a reduction in growth rate in patients with EHPVO is the reduction of the liver blood flow due to the formation of portalsystemic collateral vessels leading to deprivation of hepatotrophic hormones interfering with the overall growth of these children $[4,7,9,10]$. Poor food intake could also be a cause of growth failure and developmental deficit [10]. However, the occurrence of growth retardation remains controversial; some studies suggest that pediatric care and appropriate treatment of complications of esophagogastric varices can ensure proper growth in these children $[3,11]$.

This study aimed to evaluate the nutritional status, dietary intake, and growth rate in children and adolescents with extrahepatic portal vein obstruction and portal hypertension.

\section{METHO D S}

Patients diagnosed with EHPVO and portal hypertension aged 1-18 years were selected for evaluation follow-up at the Pediatric Hepatology outpatient clinic of the School of Medical Sciences, Universidade Estadual de Campinas (UNICAMP), between May 2010 and August 2012, but the patients were followed-up for at least six months within this set period of time. The present study was carried out according to the principles laid down in the Declaration of
Helsinki, and it was approved by the Research Ethics Committee of the School of Medical Sciences, Protocol $n^{\circ}$ 270/2010. The Informed Consent Form was signed by the patients' parents or guardians. Patients with diseases other than EHPVO and portal hypertension and those who had been submitted to portosystemic shunt were excluded from the study.

A mechanical scale with a $150 \mathrm{~kg}$ capacity and readability of $100 \mathrm{~g}$ with a $2 \mathrm{~m}$ length stadiometer height rod, readability of $1 \mathrm{~mm}$, was used to measure weight and height, respectively. Arm circumference was measured at the level of the mid-point between the acromiale and the radiale, and Triceps Skinfold Thickness (TST) was measured at the posterior midline of the upper arm using a scientific adipometer. This is a longitudinal study including two evaluations, at an initial (evaluation 1) and a final evaluation (evaluation 2) with a threemonth minimum interval between them. Two anthropometric measurements were performed, and a questionnaire containing questions about patient's personal information, age, medication use, occurrence of bleeding, food consumption, and consumption frequency were administered.

Body Mass Index (BMI) was calculated based on the weight and height measurements. Using the World Health Organization reference curves, Weight-for-Age (W/A) for children (from birth to 10 years of age), Height-for-Age $(\mathrm{H} / \mathrm{A})$, and BMI-for-Age (BMI/A) for children and adolescents (from birth to 19 years of age), were subsequently classified as follows: W/A: Z<-3: very low W/A; $\mathrm{Z} \geq-3 \mathrm{Z}<-2$ : low W/A; $\mathrm{Z} \geq-2 \mathrm{Z} \leq+2$ : normal W/A; $Z>+2: H / A$. Height-for-age classification: $Z<-3$ : very low $H / A$; $Z \geq-3 Z<-2$ : low $H / A$; $Z \geq-2$ : normal $\mathrm{H} / \mathrm{A}$. BMI-for-Age classification (BMI/A): Z<-3: severe thinness; $Z \geq-3 Z Z<-2$ : thinness; $Z \geq-2 Z \leq+1$ : eutrophic; $Z \geq+1$ and $Z \leq+2$ : at risk of overweight (overweight for those over 5 years old); $Z \geq+2$ $\mathrm{Z} \geq+3$ : overweight (obesity for those over 5 years old); Z>+3: obesity (severe obesity for those over 5 years old) $[12,13]$. The Mid-Arm Muscle Circumference (MAMC) was calculated based 
on the measurements of arm circumference and TSF using the equation: MAMC $(\mathrm{cm})=A C(\mathrm{~cm})$ $\pi \mathrm{X}(\mathrm{TSF}(\mathrm{mm}) / 10)$. Nutritional status classification was then based on the percentage of adequacy, using the following equation: MAMC Adequacy $(\%)=($ MAMC obtained $(\mathrm{cm}) / M A M C$ 50th percentile) $\times 100$, according to the MAMC values in the 50th percentile of Frisancho's table [14].

In both evaluations (1st and 2nd), a dietary questionnaire comparing dietary intake with the recommended daily energy intake (I1/R1 and 12/R2) was administered. Patient's dietary intake in kilocalories (kcal) was obtained using the Nutrition Support Software Nutwin ${ }^{\circledR}$ (Universidade Federal de São Paulo, SP, Brazil). Those values were then compared with the Recommendations for daily energy intake ( $\mathrm{kcal}$ ), according to the Harris \& Benedict equation [15]. Growth rate was calculated using the $\mathrm{H} / \mathrm{A}$ Z-scores measured in the first and second evaluations, by subtracting the first Z-score value from the second $[16,17]$.

\section{RES U L T S}

Of the 58 patients diagnosed with EHPVO and portal hypentension treated in Pediatric Hepatology outpatient clinic at UNICAMP, 22 patients were included in the present study. There was predominance of males (15/22). Patient ages ranged from $1.58-16.50$ years, with a mean age of 8.08 years (Standard Deviation$\mathrm{SD}=3.14$ years). The diagnostic of EHPVO was based on the presence of hematemesis $(n=16)$ or umbilical vein catheterization $(n=6)$. Fifteen had Splenomegaly (Table 1). The average time between the assessments was 10.55 months ( $S D=6$ months).

According to the body mass index/ age reference curves, it was found that most patients were considered as eutrophic $(n=18)$. There were also some cases of overweight $(n=2)$ and obesity $(n=1)$, nutritional statuses that remained the same throughout the study period. One patient was found underweight in evaluation 1, but this patients' body weight improved, and in evaluation 2, this patient was classified as eutrophic. There was a significant difference between the first and second evaluation in the measurements of weight $(p<0.001)$, height $(p<0.001), \mathrm{BMI}(p<0.017)$, and MAMC $(p=0.0018)$ (Table 2$)$; there was no significant differences in the $p$-values of the W/A, $H / A$, and BMI/A measurements: 0.1255; 0.0882, and 0.4680 , respectively, according to the Wilcoxon method (Table 3).

Based on the dietary intake questionnaire, energy intake was significantly higher than the recommended intake values in both evaluations (I/R1 and I/R2) ( $p=0.0001)$ (Table 4).

\section{DISCUSSION}

There is a lack of studies on nutritional status of children and adolescents with EHPVO. Most patients included in this study were classified as well-nourished. Comparing the anthropometric measurements made at the beginning and at the end of this study, there was a significant increase in the MAMC, which is an important parameter to evaluate nutritional

Table 1. Clinical and demographic assessment according to gender in evaluation 1. Campinas (SP), Brazil (2012).

\begin{tabular}{|c|c|c|c|c|c|c|c|}
\hline \multirow{3}{*}{ Gender } & \multicolumn{4}{|c|}{ Age (years) } & \multirow{2}{*}{ Hematemesis } & \multirow{2}{*}{ Catheterization } & \multirow{2}{*}{ Splenomegaly } \\
\hline & & Median & Maximum & Minimum & & & \\
\hline & $n$ & $\%$ & $\%$ & $\%$ & $n$ & $n$ & $n$ \\
\hline Female & 7 & 8.50 & 16.4 & 3.8 & 2 & 5 & 4 \\
\hline Male & 15 & 7.25 & 12.5 & 1.6 & 4 & 11 & 11 \\
\hline
\end{tabular}


Table 2. Anthropometric data in evaluations (1) and (2) and difference between these evaluations (Diff. 1 and 2). Campinas (SP), Brazil (2012).

\begin{tabular}{|c|c|c|c|c|}
\hline Anthropometric data & $n$ & Median & Minimum & Maximum \\
\hline Weight (1) kg & 22 & 25.40 & 10.90 & 57.10 \\
\hline Weight (2) kg & 22 & 27.95 & 13.40 & 58.40 \\
\hline Diff weight 1 and $2 \mathrm{~kg}$ & 22 & 2.35 & 0.30 & 15.20 \\
\hline Height (1) cm & 22 & 125.00 & 82.50 & 164.30 \\
\hline Height (2) cm & 22 & 129.10 & 91.60 & 164.30 \\
\hline Diff height 1 and $2 \mathrm{~cm}$ & 22 & 4.10 & 0.00 & 14.60 \\
\hline $\mathrm{BMI} / \mathrm{A}(1) \mathrm{kg} / \mathrm{m}^{2}$ & 22 & 16.20 & 13.06 & 21.46 \\
\hline $\mathrm{BMI} / \mathrm{A}(2) \mathrm{kg} / \mathrm{m}^{2}$ & 22 & 16.29 & 13.12 & 24.90 \\
\hline Diff BMI 1 and 2kg/m² & 22 & -0.40 & 0.18 & 3.44 \\
\hline MAMC (1) & 22 & 15.65 & 8.40 & 20.60 \\
\hline MAMC (2) & 22 & 16.10 & 11.80 & 24.80 \\
\hline Diff MAMC 1 and 2 & 22 & 1.51 & -0.80 & 4.70 \\
\hline
\end{tabular}

Diff: Difference between evaluations 1 and 2 .

Table 3. Anthropometric data in evaluations (1) and (2) and difference between these evaluations (Diff. 1 and 2). Campinas (SP), Brazil (2012).

\begin{tabular}{llccc}
\hline Anthropometric data & $\mathrm{n}$ & Median & Minimum & Maximum \\
\hline W/A (1) Z-score & 16 & -0.41 & -2.40 & 4.58 \\
W/A (2) Z-score & 16 & -0.26 & -2.28 & 5.59 \\
H/A (1) Z-score & 22 & -0.16 & -2.68 & 3.48 \\
H/A (2) Z-score & 22 & -0.09 & -2.98 & 4.76 \\
BMI/A (1) Z-score & 22 & -0.07 & -3.38 & 2.80 \\
BMI/A (2) Z-score & 22 & 0.14 & -2.39 & 2.90 \\
Growth rate Z-score & 22 & -0.06 & -1.18 & 1.10 \\
\hline
\end{tabular}

W/A: Weight-for-Age; H/A: Height-for-Age; BMI: Body Mass Index.

Table 4. Energy intake compared to the recommended values in evaluations (1) and (2) and difference between these evaluations (Diff. 1 and 2). Campinas (SP), Brazil (2012).

\begin{tabular}{lccc}
\hline Data & Median & Minimum & Maximum \\
\hline I/R (1) kcal & 662.00 & -354.00 & 1848.00 \\
I/R (2) kcal & 622.00 & -50.00 & 2097.00 \\
Diff I/R 1 and 2 & -1065.00 & -13.50 & 1511.00 \\
\hline
\end{tabular}

I/R: Energy Intake and Energy Intake Recommendation ratio; Diff I/R: Difference between both evaluations.

status because it represents gain of muscle mass (fat-free edema-free body mass).

Sarin et al. [18] compared 61 children with EHPVO with healthy controls and observed significant reduction in the H/A parameter.
The author also suggested that endoscopic treatment does not prevent growth retardation. It should be noted, however, that EHPVO is a long-standing disease and that among the patients evaluated by Sarin \& Agarwal [4], only 
9.8\% had $\mathrm{H} / \mathrm{A}$ below $85.0 \%$ of the expected value, and $36.0 \%$ were classified as having acute malnutrition. In other words, less than $10.0 \%$ of the cases of malnutrition could be due to portal vein thrombosis, which is considered a significant factor affecting growth due to its long-term occurrence and/or associated phenomena.

Similarly, Mehrotra et al. [10] studied 33 children with EHPVO and found significantly lower Z-scores for H/A in patients with EHPVO. It was also observed that half of the patients had weight and height below the 5th percentile, and the weight-for-height, an indicator of acute aggravated nutritional status, was adequate, according to the National Center for Health Statistics. These data indicate that there was no growth deficit at the time of evaluation, and it was more likely related to a previous disrupted weight gain pattern in these children [10].

Mir et al. [8] compared growth-related hormones in 30 children with EHPVO with those of healthy controls and investigated the effect of shunt surgery on growth parameter in 12 children. The authors found a decrease in weight and height standards associated with growth hormone resistance, which improved after shunt surgery. However, they compared the growth-related hormone profiles of malnourished children and healthy children, which could reflect bias since nutritional status may have influenced the studied hormone profiles $[8,19]$.

Nevertheless, Alvarez et al. [1,2] did not find growth retardation in a group of 40 children with EHPVO. In addition, in their studies there was an increase in growth rate after surgical shunt; however, the Z-scores for H/A were not recorded before and after surgery.

Dietary intake might have influenced the results due to the energy intake greater than or equal to the recommended values (Table 4). However, dietary intake was not associated with growth rate in both evaluations carried out in the present study. Frequent consumption of foods with high energy density, which do not necessarily have good nutritional content, can explain the cases of overweight and obesity found.

In the present study, it was found adequate nutritional status and growth rate despite the fact that the nutritional status did not significantly affect the growth rate $(p=0.599)$.

\section{CONCLUSION}

Extrahepatic portal vein obstruction and portal hypertension were not shown to be factors predisposing to malnourishment in the present study since the patients evaluated had adequate nutritional status and significant improvement in MAMC.

\section{CONTRIBUTORS}

PF MARQUES and MAB BRANDÃO contributed to data collection and tabulation, to the analysis of results, and to the conception and design of this study. EA LOMAZI contributed to the analysis of results and to the conception of and design of this study. G HESSEL contributed to the analysis of results. RV ALCANTARA and ML FERREIRA contributed to data collection

\section{REFERE N CES}

1. Alvarez F, Bernard $O$, Brunelle F, Hadchouel $P$, Odièvre $M$, Alagille $D$. Portal obstruction in children. I. Clinical investigation and hemorrhage risk. J Pediatr. 1983;103(5):696-702.

2. Alvarez F, Bernard $O$, Brunelle F, Hadchouel $P$, Odièvre $M$, Alagille $D$. Portal obstruction in children. II. Results of surgical portosystemic shunts. J Pediatr. 1983;103(5):703-7.

3. Schettino GC, Fagundes ED, Roquete ML, Ferreira $A R$, Penna FJ. Portal vein thrombosis in children and adolescents. J Pediatr. 2006;82(3):171-8.

4. Sarin SK, Agarwal SR. Extrahepatic portal vein obstruction. Semin Liver Dis. 2002;22(1):43-58.

5. Wang JT, Zhao HY, Liu YL. Portal vein thrombosis. Hepatobilliary Pancreat Dis Int. 2005;4(4):515-8.

6. Ferri PM, Ferreira AR, Fagundes DT, Liu SM, Albuquerque NN, Botelho FC, et al. Trombose 
de veia porta em crianças e adolescentes: revisão de literatura. Rev Med Minas Gerais. 2011;21(4Supl. 1):S36-S44.

7. Kato $T$, Romero R, Koutouby R, Mittal NK, Thompson JF, Schleien $\mathrm{CL}$, et al. Portosystemic shunting in children during the era of endoscopic therapy: Improved postoperative growth parameters. J Pediatr Gastroenterol Nutr. 2000;30(4):419-25.

8. Mir TA, Misgar RA, Laway BA, Shah OJ, Shah ZA, Zargar SA. Prevalence and pattern of growth abnormalities in children with extrahepatic portal vein obstruction: Response to shunt surgery. Indian J Endocrinol Metab. 2016;20(6):763-6.

9. Bucuvalas JC, Cutfield W, Horn J, Sperling MA, Heubi JE, Campaigne $B$, et al. Resistance to the growth hormone in children with chronic liver disease. J Pediatr. 1990;117(3):397-402.

10. Mehrotra RN, Bhatia V, Dabadghao P, Yachha SK. Extrahepatic portal vein obstruction in children: Anthropometry, growth hormone and insulinlike growth factor I. J Pediatr Gastroenterol Nutr. 1997;25(5):520-23.

11. Bellomo-Brandão MA, Morcillo AM, Hessel G, Cardoso SR, Servidoni MFPC, Costa-Pinto EAL. Growth assessment in children with extra-hepatic portal vein obstruction and portal hypertension. Arq Gastroenterol. 2003;40(4):247-50.

12. World Health Organization. Growth reference data for 5-19 years: 2006 and 2007. Geneva:
WHO; 2007 [cited 20129 24]. Available from: http://www.who.int/growthref/who2007_bmi_ for_age/en/index.html

13. World Health Organization. Physical status: The use and interpretation of anthropometry. Technical Report Series, n 854. Geneva: WHO; 1995.

14. Frisancho AR. New norms of upper limb fat and muscle areas for assessment of nutritional status. Am J Clin Nutr. 1981;34(11):2540-5.

15. Harris J, Benedict F. A biometric study of basal metabolism in man. Public $n^{\circ} 279$. Washington: Carnegie Institute of Washington; 1919.

16. Cole TJ. Some questions about how growth standards are used. Horm Res. 1996;45(2):18-23.

17. Zeferino AMB, Barros Filho AA, Bettiol H, Barbieri MA. Acompanhamento do crescimento. J Pediatr. 2003;79(Supl.1):S23-S32.

18. Sarin SK, Sollano JD, Chawla YK, Amarapurkar D, Hamid S, Hashizume M, et al. Consensus on extra-hepatic portal vein obstruction. Liver Int. 2006;26(5):512-9.

19. Fazeli PK, Klibanski A. Determinants of growth hormone resistance in malnutrition. J Endocrinol. 2014;220(3):R57-R65.
Received: April 24, 2016

Final version: April 6, 2017 Approved: April 17, 2017 
